\title{
Psychological aspects of Alopecia Areata
}

\author{
Payal Sharma ${ }^{1}$ \\ Austin Fernandes ${ }^{2}$ \\ Anup Bharati \\ Sushma Sonavane ${ }^{4}$ \\ Nilesh Shah \\ Sagar Karia ${ }^{6}$ \\ Avinash De Sousa ${ }^{7}$
}

${ }^{1}$ Resident Doctor; ${ }^{2}$ Senior Resident Doctor;.${ }^{3}$ Asst. Professor; ${ }^{4}$ Addl. Professor; ${ }^{5}$ Professor and Head;

${ }^{6}$ Speciality Medical Officer; ${ }^{7}$ Research Associate

Department of Psychiatry, Lokmanya Tilak Municipal Medical College, Mumbai

E-mail - dranupsb@gmail.com

\begin{abstract}
Alopecia areata is a chronic probable auto immune skin disorder characterised by hair loss over the body. Though its psychological status has been debated over the ages presently we have research that points towards a psychosomatic causation of the disorder. The present review paper looks at the psychological factors in alopecia areata, the various studies and prevalence of psychiatric problems in this population. The approaches to treatment have not been laid out via rigorous studies or large number of psychological interventions for both the patient and the family shall be useful in the management of this condition. There is a need for dermatologists to liaison
\end{abstract} clinical trials and have to be decided on a case to case basis. Along with medication a with mental health professionals when it concerns the long term and holistic management of alopecia areata.

Key words : Alopecia areata, psychodermatology, psychological factors, alopecia.

\section{INTRODUCTION}

Alopecia Areata (AA) is a chronic inflammatory non scarring skin condition that leads to patchy hair loss over the scalp and can progress to diffuse hair loss all over the body [1]. Spontaneous regrow of hair and subsequent reloss is also known. It occurs in $60 \%$ cases before the age of 20 years and a family history of the illness is seen in $20 \%$ cases [2]. It is often associated with autoimmune disorders like vitiligo, pernicious anemia and diabetes though an autoimmune basis of its own etiology is unproven [3].

The role of psychological factors and skin diseases has always been studied. The entity of psycho-cutaneous disorders where psychological factors may affect skin disease and the converse also holds true is well known for many skin disorders like psoriasis, acne, alopecia areata and other debilitating skin disorders [4]. In the present 
paper we focus on psychological issues in alopecia areata and the various studies done on the same. The realm of psychological factors has moved even from skin to hair and today we have literature that supports the evidence for psychotrichology a branch that elucidates the role of psychological and psychosocial as well as psychosomatic factors in hair disorders [5].

\section{METHOD OF CONDUCTING THIS REVIEW}

For the purpose of this review the search methods included using databases like Medline, Pubmed and Google scholar. Words like alopecia areata, psychological issues in alopecia areata, depression in alopecia areata and other similar notations were searched for and original research papers, review articles as well brief communications and case reports were analysed. Authors were contacted for full text of many papers. The search yielded a total of 212 different papers and articles where subjects were less than 20 and methodologies were doubtful were rejected. A total of 129 papers were reviewed for this paper. Of these 12 were related review papers and the rest were original research articles. Only 2 reviews on the subject were available while 10 were review papers on overlapping subjects. Individual studies have not been reviewed as most findings were similar but rather a synthesis of findings across various papers has been presented in this article. This has been supplemented with clinical experiences we have in working in liaison with the dermatology department of a tertiary general hospital in Mumbai. We were unable to locate any meta-analysis with regard to the topic of this review. In fact the workdone in this area is so varied that such an analysis is probably never possible.

\section{PSYCHOSOMATIC MODEL FOR ALOPECIA AREATA}

Alexithymia is a phenomenon that has been described as a personality trait characterised by difficulty in differentiating, describing and labelling emotions. It is the core psychology construct that has been implicated in psychosomatic disorders [6]. Though associations between dermatological disorders and alexithymia are scarce, a growing evidence indicates its role in various skin disorders like vitiligo, psoriasis, alopecia areata, urticaria and atopic dermatitis [7]. The trait of alexithymia has been linked to insecure childhoods with adverse parenting and traumatic childhood experiences [8].

Over the years our understanding of the etiopathogenesis of alopecia areata has evolved as a polarized dichotomy between the mind and the body and it is only of late that we are able to envisage a connection between the two. Literature is abundant with papers of sudden hair loss during stress and comcomitant psychological and psychosocial determinants of alopecia areata [9]. The psychological implications of alopecia areata range from the role of life events implicated in its causation to the presence of depression and anxiety along with disruption in family functionality and adverse effects on health related quality of life [10]. It is well known that alopecia areata is affected by the endocrine and immune systems and we have literature that supports the role of psychological factors in the modulation of these systems and the causation of autoimmune disorders [11]. The role of stress in these disorders is well known and data has provided us evidence that psychological factors play a role in precipitating alopecia areata [12]. 


\section{ANXIETY, STRESS AND DEPRESSION IN ALOPECIA AREATA}

Stress is a wide construct and researchers have varying definitions of what constitutes stress. Researchers also vary in what are momentary or long term endured stresses [13]. This makes it difficult to interpret findings from research papers on the subject and most studies take no cognizance of intrapsychic and various individual trajectories that may be at play in the individual patient [14]. Anxiety and depression have been reported widely across various studies in patients with alopecia areata. The range of patients affected by the disorders are $30-80 \%$ across studies [15-18]. Varied prevalence can be attributed to differences in patient population and varied scales and their cut offs used in the diagnosis [18]. Most of the studies are post disease appearance and pre and post comparisons are not possible as longitudinal studies are not reported [19]. Feelings of insecurity and inferiority along with passivity in response to emotions has been reported in this patient population [20]. Many case studies have reported tracing the problem to adverse childhood experiences and developmental perspectives have been elucidated [21]. Long term chronic endurance of stress is a common factor compared to recent trauma while precipitation of alopecia areata by a fresh traumatic event has been reported across studies [22]. Suicidal tendencies have been reported in 5 to $15 \%$ cases across studies [23]. Children with alopecia areata report negative events in childhood and traumatic events perceived as a loss [24]. This loss was a major threat to the child and often precipitated onset of the disorder. Children with alopecia areatahave reported more anxiety and depression than normal controls coupled with greater emotional problems. Early stress often leads to the development of a personality pattern that makes one more vulnerable to further stress and thus primes the internal organs including the skin and scalp to develop stress induced disorders [25].

\section{PERSONALITY PROFILES IN ALOPECIA AREATA}

Alopecia areata patients have a characteristic personality profile with low novelty seeking, low reward dependence and low self transcendence [26]. Children with alopecia areata are more withdrawn, depressed and aggressive showing depression in nearly $40-50 \%$ cases [27]. There are not many studies on personality characteristics of these patients and neither has the incidence of personality disorders in this group been studied. There is one research that documents elevated depression, psychasthenia and social introversion sub scales on assessment on the Minnesota Multiphasic Personality Inventory (MMPI) in this group [28].

\section{NEUROBIOLOGICAL INSIGHTS INTO ALOPECIA AREATA}

The influence of psychological factors in alopecia areata though well established has been debated. Recent studies have tried to explain a neurobiology for the same [29]. Acute emotional stress may precipitate alopecia areata by activation of over expressed type $2 \mathrm{~b}$ corticotrophin releasing hormone receptors around the hair follicle leading to local inflammation [30]. Release of substance $P$ from the nerves in response to stress has been reported and the same is noted in the hair follicles in alopecia areata. Substance $P$ degrading enzymes have been expressed in the hair follicles in both acute and chronic alopecia areata [31]. Similar neurobiology implications have been noted in stress induced psychiatric disorders like major depression, 
generalized anxiety disorder and phobias which have also been noted as comorbidity in alopecia areata [32].

\section{QUALITY OF LIFE IN ALOPECIA AREATA}

Quality of life is a broad concept and is aimed at whether a disorder limits a patient's ability to fulfil a normal role and also assesses burden and outcomes of treatments offered. It is defined as the subjective perception of the impact on health status including the disease and its treatment and on physical, psychological and social functioning and well being of patients [33]. This is a very important indicator in disorders like alopecia areata because the disorder has strong impact on social relationships, daily basis activities and psychosocial status [34]. Effectiveness of treatment in alopecia areata can also be assessed using quality of life indicators along with social and financial burden placed by the disorder on patients [35]. Studies using various quality of life instruments have demonstrated a detrimental effect on quality of life in these patients while improvement in quality of life with improvement and recovery of disease status is also known [36-37].

\section{LIFE EVENTS AND ALOPECIA AREATA}

Life events play an important role in causation of alopecia areata. Life events alone are not sufficient by themselves to reach etiological significance [38]. The most important factor that influences stress is the challenge posed to the individual by a specific stimulus. There is another important factor when looking at the role of stress in the etiology of alopecia areata. A stressful life event may mean different things to different people. People who interpret events as having negative consequences for them will be more vulnerable to emotional and immunological sequelae than others [39]. Both state anxiety and trait anxiety have been raised in patients with alopecia areata [40]. State anxiety when raised incraeses the clinical manifestations of alopecia areata. It is possible that trait anxiety in association with high levels of perceived stress can play a role in triggering the disease process in alopecia areata while stressful events can trigger alopecia areata exacerbations once the disease process is established [41].

\section{FEMALE PATIENTS WITH ALOPECIA AREATA}

Female patients with alopecia areata have more emotional overtones and adding to the worry may be a trivialization of the issues by inexperienced physicians [42]. At a psychological level it is very important that apart from a correct diagnosis the patient's concerns must be directly and specifically solicited and addressed. The patients perspectives on hair loss and his expectations from treatment must be acknowledged. Patients must be psychoeducated about the normal hair cycle and hair growth while emphasising the need for patience while aiming at good cosmetic recovery [43]. Hair is a vital component cosmetically for a woman's beauty. The length, colour and texture of hair are often ways and means of estimating the time given by a woman in the care of the self [44]. There is no doubt that in certain cultures hair is symbol of both ethnic beauty and inner strength as well as divinity. There is no question that in a disorder like alopecia areata where hair is affected one will experience a loss of self esteem and develop a dislike and repugnance for ones own looks and appearance [45]. Self esteem and social relationships are thus affected in both sexes however more for female patients. This is a clear reason for the adverse psychosocial impact caused by 
alopecia areata. This issue needs to be addressed while educating patients about the disorder and counselling in this regard is a must when we aim at a better understanding and recovery from the disorder [46].

\section{COMMUNICATION AND COMPLIANCE IN ALOPECIA AREATA}

Communication skills are a must when dealing with a patient of alopecia areata as good communication is vital in the recovery process. Communication has to include listening to the patient, understanding the patient, informing about various tests and diagnostic procedures as well as therapeutic considerations and prognosis [47]. It also involves convincing the patient while giving hope and jointly rejoicing over therapeutic progress. One has to also avoid a personal dominant behaviour and stereotype prejudices [48]. Communication will also play a role in ensuring compliance. Treatment success relies on patient compliance and that in turn relies on confidence and motivation [49]. Some of the major barriers to treatment compliance are denial of the problem, fear of side effects, treatment costs, poor previous experience and lack of trust. One must prescribe treatment options that will be beneficial along with a discussion on side effects as well as advice on coping and minimising them [50]. A good physician patient relationship is the key to achieving success in the management of a disorder like alopecia areata [51].

\section{ROLE OF PSYCHOLOGICAL INTERVENTIONS IN ALOPECIA AREATA}

There is a need for dermatologists to work in liaison with mental health professionals when it comes to the successful management of alopecia areata a disorder which is dermatological in origin and yet has intense psychological ramifications. Data available with psychotherapy intervention in alopecia areata is minimal. There is a favorable result with insight oriented psychotherapy [52], family therapy [53] and hypnotherapy [54]. The techniques focus on training of general coping strategies and body image improvement strategy. Emotional regulation is another area where intervention is needed along with psycho education of the family and patient [55]. Patient education and counselling along with counselling and psychoeducation of relatives in helping patients cope is anotherarea which is important [56]. Information on the use of psychotropic drugs as well as antidepressants in this population as well as data on comparative studies or trials in this regard was unavailable. Clinical experience suggests that the decision shall be on case to case basis.

\section{CONCLUSIONS}

Thus as we can see literature on various psychological issues in alopecia areata is present though sparse. There is an urgent need to promote further research in the area of psychology and psychological interventions for the management of this disorder. Treatment related studies are absent and there is a need for better documentation of management procedures from the mental health perspective. There is a growing need for dermatologists to liaison with mental health professionals in the long term and holistic management of this complex and vexing disorder. 


\section{REFERENCES}

1. Alkhalifah A, Alsantali A, Wang E, McElwee KJ, Shapiro J. Alopecia areataupdate : part 1 clinical picture, histopathology and pathogenesis. J Am Acad Dermat 2010;62(2):178-88.

2. Sharma VK, Dawn G, Kumar B. Profile of alopecia areata in Northern India. Int J Dermatol $1996 ; 35: 22-7$.

3. Wasserman D, Guzman-Sanchez DA, Scott K, McMichael A. Alopecia areata. Int J Dermatol 2007;46:121-31.

4. Jafferany M. Psychodermatology : a guide to understanding common psychocutaneous disorders. Prim Care Companion J Clin Psychiatry 2007;9:203-13.

5. Harth W, Blume-Peytavi U. Psychotrichology: psychosomatic aspects of hair diseases. JDDG: J der Deutsch Dermatol Gesell 2013;11(2):125-135.

6. Lumley MA, Stettner L, Wehmer F. How are alexithymia and physical illness linked? A review and critique of pathways. J Psychosom Res 1996;41(6):505-18.

7. Poot F, Sampogna F, Olnnis L. Basic knowledge in psychodermatology. J Eur Acad Dermatol Venereol 2007;21(2):227-34.

8. Larsen JK, Brand N, Bermond B, Hijman R. Cognitive and emotional characteristics of alexithymia: A review of neurobiological studies. J Psychosom Res 2003;54(6):533-41.

9. Güleç AT, Tanrıverdi N, Dürü Ç, Saray Y, Akçalı C. The role of psychological factors in alopecia areata and the impact of the disease on the quality of life. Int J Dermatol 2004;43(5):352-56.

10. Hunt N, McHale S. The psychological impact of alopecia areata. BMJ 2005;331(7522):9513.

11. Ruiz-Doblado S, Carrizosa A, Garcia-Hernandez MJ. Alopecia areata: Psychiatric comorbidity and adjustment to illness. Int J Dermatol 2003;42:434-7.

12. Koo JY, Shellow WV, Hallman CP, Edwards JE. Alopecia areata and increased prevalence of psychiatric disorders. Int J Dermatol 1994;33:849-50.

13. Manolache L, Benea V. Stress in patients with alopecia areata and vitiligo. J Eur Acad Dermatol Venereol 2007;21(7):921-8.

14. Garcia-Hernandez MJ, Ruiz-Doblado S, Rodriguez-Pichardo A, Camacho F. Alopecia areata: stress and psychiatric disorders: a review. J Dermatol 1999;26:625-32.

15. Gulec AT, Tanriverdi N, Duru C, Saray Y, Akcali C. The role of psychological factors in alopecia areata and the impact of the disease on quality of life. Int J Dermatol 2004;43(5):352-6.

16. Chu SY, Chen YJ, Tseng WC, Lin MW, Chen TJ, Hwang CY, Chen CC, Lee DD, Chang YT, Wang WJ, Liu HN. Psychiatric comorbidities in patients with alopecia areata in Taiwan : a case control study. Br J Dermatol 2012;166(3):525-31.

17. Alfani S, Antinone V, Mozzetta A, Di Pietro C, Mazzanti C, Stella P, Raskovich D, Abeni D. Psychological status of patients with alopecia areata. Acta Derm Venereol 2012;92(3):3046.

18. Bashir K, Dar NR, Rao SU. Depression in adult dermatology outpatients. J Coll Physicians Surg Pak 2010;20(12):811-3.

19. Grahovac T, Ruzić K, Sepić-Grahovac D, Dadić-Hero E, Radonja AP. Depressive disorders and alopecia areata. Psychiatr Danub 2010;22(2):293-5.

20. Picardi A, Pasquini P, Cattaruzza MS, Gaetano P, Baliva G, Melchi CF, Papi M, Camaioni D, Tiago A, Gobello T, Biondi M. Psychosomatic factors in first onset alopecia areata. Psychosomatics 2003;44(5):374-81.

21. van der Steen $P$, Boezeman J, Duller P, Happle R.Can alopecia areata be triggered by emotional stress? An uncontrolled evaluation of 178 patients with extensive hair loss. Acta Derm Venereol 1992;72(4):279-80.

22. Taheri R, Behnam B, Tousi JA, Azizzade M, Sheikhvatan MR. Triggering the role of stressful life events in patients with alopecia areata. Acta Dermato Venereol Croat 2012;20(4):24650.

23. Gupta MK, Gupta AK. Depression and suicidal ideation in dermatology patients with acne, alopecia areata, atopic dermatitis and psoriasis. Br J Dermatol 1999;139(5):846-50. 
24. Bilgiç O, Bilgiç A, Bahalı K, Bahali AG, Gürkan A, Yılmaz S. Psychiatric symptomatology and health related quality of life in children with alopecia areata. J Eur Acad Dermatol Venereol 2013; Nov 16: Epub ahead of print.

25. Hankinson A, McMillan H, Miller J. Attitudes and perceptions of school aged children towards alopecia areata. JAMA Dermatol 2013;149(7):877-9.

26. Beard HO. Social and psychological implications of alopecia areata. J Am Acad Dermatol $1986 ; 14(4): 697-700$.

27. Reeve EA, Savage TA, Bernstein GA. Psychiatric diagnoses in children with alopecia areata. J Am Acad Child Adolesc Psychiatry 1996;35(11):1518-22.

28. Monselise A, Bar-On R, Chan L, Leibushor N, McElwee K, Shapiro J. Examining the relationship between alopecia areata, androgenetic alopecia, and emotional intelligence. J Cutan Med Surg 2013;17(1):46-51.

29. Gupta MA, Gupta AK, Schork NJ, Ellis CN. Depression modulates pruritus perception: A study of pruritus, atopic dermatitis, and chronic idiopathic urticaria. Psychosom Med $1994 ; 56: 36-40$.

30. Katsarou-Katsari A, Singh LK, Theoharides TC. Alopecia areata and affected skin CRH receptor upregulation induced by acute emotional stress. Dermatology 2001;203:157-61.

31. Toyoda M, Makino T, Kagoura M, Morohashi M. Expression of neuro peptide-degrading enzymes in alopecia areata: An immunohistochemical study. Br J Dermatol 2001;144:4654.

32. Basavaraj $\mathrm{KH}$, Navya MA, Rashmi R. Relevance of psychiatry in dermatology : present concepts. Indian J Psychiatry 2010;52:270-5.

33. Qi S, Xu F, Sheng Y, Yang Q. Assessing quality of life in patients with alopecia areata in China. Psychol Health 2014; Mar 17:Epub ahead of print.

34. Shi Q, Duvic M, Osei JS, Hordinsky MK, Norris DA, Price VH, Amos CI, Christiano AM, Mendoza TR. Health-Related Quality of Life (HRQoL) in alopecia areata patients-a secondary analysis of the National Alopecia Areata Registry Data. J Investig Dermatol Symp Proc 2013;16(1):S49-50.

35. Inui S, Inoue T, Itami S.Psychosocial impact of wigs or hairpieces on perceived quality of life level in female patients with alopecia areata. J Dermatol 2013;40(3):225-6.

36. Ghajarzadeh M, Ghiasi M, Kheirkhah S. Associations between skin diseases and quality of life: a comparison of psoriasis, vitiligo, and alopecia areata. Acta Med Iran 2012;50(7):511-5.

37. Fabbrocini G, Panariello L, De Vita V, Vincenzi C, Lauro C, Nappo D, Ayala F, Tosti A.Quality of life in alopecia areata : a disease specific questionnaire. J Eur Acad Dermatol Venereol 2013;27(3):e276-81.

38. Paus R, Arck P. Neuroendocrine perspectives in alopecia areata : does stress play a role. J Invest Dermatol 2009;129(6):1324-6.

39. Picardi A, Abeni D. Stressful life events and skin diseases : disentangling the evidences from the myths. Psychother Psychosom 2001;70(3):118-36.

40. Brajac I, Tkalcic M, Dragojević DM, Gruber F. Role of stress, stress perception and trait anxiety in the onset and course of alopecia areata. J Dermatol 2003;30(12):871-8.

41. García-Hernández MJ, Ruiz-Doblado S, Rodriguez-Pichardo A, Camacho F. Alopecia areata, stress and psychiatric disorders : a review. J Dermatol 1999;26(10):625-32.

42. Trueb R. The difficult hair loss patient : a particular challenge. Int J Trichology 2013;5(3):110-4.

43. Teutsch C. Patient doctor communication. Med Clin North Am 2003;87:1115-45.

44. Lundin M, Chawa S, Sachdev A, Bhanusali D, Seiffert-Sinha K, Sinha AA. Gender differences in alopecia areata. J Drugs Dermatol 2014;13(4):409-13.

45. Treub RM. Female alopecia : guide to successful management. Heidelberg, Berlin: Springer ; 2013.

46. Cash TF. The psychosocial consequences of androgeneticalopecia : a review of research literature. Br J Dermatol 1999;130:868-72.

47. Price VH. Alopecia areata : clinical aspects. J Invest Dermatol 1991;96:S68-70.

48. Kos L, Conlon J. An update on alopecia areata, Curr Opin Pediatr 2009;21:475-80. 
49. Kalabokes VD. Alopecia areata: Support groups and meetings - how can it help your patient. Dermatol Ther 2011;24(3):302-4.

50. Matzer F, Egger JW, Kopera D. Psychological stress and coping in alopecia areata : a questionnaire survey and qualitative study among 45 patients. Acta Derm Venereol $2011 ; 91(3): 318-27$.

51. Harrison S, Bergfeld W. Diffuse hair loss : its triggers and management. Cleve Clin J Med 2009;76(6):361-7.

52. Garg S, Messenger AG. Alopecia areata : evidence based treatments. Semin Cutan Med Surg 2009;28(1):15-8.

53. Sawant N, Chikhalkar S, Mehta V, Ravi M, Madke B, Khopkar U. Androgenetic alopecia : quality of life and associated lifestyle patterns. Int J Trichology 2010;2(2):81-5.

54. Willemsen R, Haentjens P, Roseeuw D, Vanderlinden J. Hypnosis and alopecia areata : long term beneficial effects on psychological well being. Acta Derm Venereol 2011;9(1):35-9.

55. Prickitt J, McMichael AJ, Gallagher L, Kalabokes V, Boeck C. Helping patients cope with chronic alopecia areata. Dermatol Nurs 2004;16(3):237-41.

56. Sehgal VN, Srivastava G, Aggarwal A, Sethi G, Adhikari T. Alopecia areata in the Indian subcontinent. Skin Med 2007;6(2):63-9.

Acknowledgements - Nil.

Conflict of Interest - Nil.

Funding - Nil. 